\title{
CONSUMER PERCEPTIONS ON QUALITY ATTRIBUTES OF LIQUID FOOD PRODUCTS: AN EMPIRICAL ANALYSIS BASED ON URBAN HOUSEHOLDS
}

\author{
W. G. M. Silva ${ }^{1}$, J. M. M. Udugama ${ }^{1}$ and U. K. Jayasinghe-Mudalige ${ }^{1}$
}

\begin{abstract}
This study examined empirically the urban consumer perceptions on key food quality attributes, including price, food safety, labeling and packaging for four liquid food products, namely bottled water, pasteurized milk, ready-to-drink fruit juices and carbonated drinks. Given the multidimensional nature of issue, the Perceptual Mapping Method explained in the Multidimensional Scaling multivariate data analysis techniques was employed to estimate and map the variations in consumers' similarity judgments on the quality attributes. A structured questionnaire was administrated with 300 households in the urban areas in the Colombo district to collect data from May to July 2011. The outcome of analysis revealed that, irrespective of the product, price plays the most significant role on consumer decision making process followed by food safety. Nevertheless, consumers were judged differently on these quality attributes as they decide on purchasing different product combinations and this behavior is correlated with the socio-economic status of a consumer. The results imply that manufacturers of these products shall pay attention to the food quality attributes in concern in their attempt to cater into their client-base and penetrate into new food markets.
\end{abstract}

Keywords: Consumer perceptions, Food quality attributes, Liquid food products, Perceptual mapping

\section{INTRODUCTION}

Liquid food product market is one of the largest growing subsectors of food industry in Sri Lanka with diverse products available for sale (i.e. bottled water, pasteurized milk, carbonated drinks, readyto-drink fruit juices and fruit cordials etc). The recent statistics from the Department of Census and Statistics of Sri Lanka (2009) indicates that the average monthly expenditure on consumption of liquid food product per person in Sri Lanka has substantially increased. For example, from the year 2007 to 2009 , it has increased by $114 \%$ for milk products (i.e. Rs. 0.94 to Rs. 2.02); $202 \%$ for soft drinks (i.e. Rs.
1.86 to Rs. 5.62 ), and $182 \%$ for bottled water (i.e. Rs. 0.35 to Rs. 0.99) and has remained almost at the same level for fruit based products (i.e. Rs. 3.19).

The facts above highlight that the markets for liquid food products are enlarging, and as a result, there exists an ample room for food businesses to supply their products to fulfill the choices of consumers. However, those adverse incidents reported in food markets, both locally and worldwide, with respect to occurrences of human illness and deaths due to poisoning caused by food-borne microbial pathogens and other agents have opened eyes of both consumers and marketers that results in 
intervention of both food marketers and government institutions to find solutions.

Abayasekara et al. (2007), on the context of bottled water industry in Sri Lanka, has implicated that those product available in the market may act as a source of outbreaks of cholera, typhoid fever and other diseases as well.

In light of these, consumer concern on the quality of food products have become one of the major and increasing preoccupations of food supply system in almost every country (Henson and Caswell, 1999) and there is no exception for Sri Lanka (Lakni and Jayasinghe-Mudalige, 2009). This has led to the fact that an ever growing number of consumers require more, valid, relevant and timely information on the quality of products they consume. Food safety and quality assurance has, therefore, become an increasing focus for governments in both developed and developing countries, food processing firms, and international trade and standardizing bodies. The more importance given to certain food quality attributes prompts implementation of enhanced quality assurance systems by food companies voluntarily apart from the strict food safety and quality standards and regulations put forward by the respective governments to regulate the industry (Buzby, 2003; Caswell, 1998).

Product quality itself is multidimensional. As a result, there is no definitive list of all attributes of quality, as the importance of such characteristics varies across circumstances and among customers (Kariyawasam et al., 2007). A number of conceptual frameworks and theoretical models have, therefore, been developed to categorize consumer behavior on attributes of food quality based on different dimensions.

In one such classification, these were classified into three major categories to explain how consumers learn about the quality of commodities what they purchase. Of which, the first category is referred to as "search" attributes, where the consumers can determine product quality at the point of purchase by looking at the product, examining and researching it (e.g., price, color). The products that belong to the second category possess "experience" attribute, where consumers are not in a position to determine product quality unless and/or until they use it after purchase (e.g., organoleptic qualities). The third category is termed as "credence" attributes, where consumers cannot judge the quality of a product even after consumption of it (e.g., pesticide residues, hormones), and as a result, it warrants more careful investigations and involvement of many parties vis-à-vis consumers, markets and governments to decide on quality assurance (Nelson, 1970; Darby and Karni, 1973). Another commonly used classification on food quality attributes in literature - Caswell classification on food quality attributes incorporates such attributes into a number of subsets as shown in Table 01 .

The objective of this study was to assess the similarities in consumer perceptions on different liquid food products in terms of various attributes of food quality as they purchase them to satisfy their needs. A number of key attributes of food quality presented in the Caswell's classification were of interest, including the price, food safety, labeling and packaging. The empirical analysis was based on the information gathered from a cross section of urban consumers and the selected liquid food products include: (i) Bottled water (BW); (ii) Pasteurized milk (PM); (iii) Ready-to-drink fruit juices (RTD), and (iv) Carbonated drinks.

\section{METHODOLOGY}

\section{Multidimensional Scaling Analysis}

Given the liquid food products listed above, a consumer, at a given point of 
time, may decide to purchase any of these products individually or as a bundle.

Further, he/she would judge on the importance of these attributes of quality from various points of views (i.e. needs, status maintenance, and constraints).
Moreover, the socio-economic and demographic characteristics associated with a consumer can play a significant role in his/her decision to purchase these products.

Table 01. Food quality attributes based on Caswell's classification

\begin{tabular}{|c|c|}
\hline Attribute of Quality & $\begin{array}{c}\text { Forms of the Attribute for the } \\
\text { Case of Milk Powder } \\
\end{array}$ \\
\hline $\begin{array}{l}\text { Food Safety } \\
\text { 1. Pathogens } \\
\text { 2. Food additives \& } \\
\text { Preservatives } \\
\end{array}$ & $\begin{array}{l}\text { Bacteria, Virus, Botulism, E-coli, } \\
\text { Added to the food, Not added to the food }\end{array}$ \\
\hline $\begin{array}{l}\text { Nutrition } \\
\text { 3. Fat \& Cholesterol } \\
\text { 4. Calories } \\
\end{array}$ & $\begin{array}{l}\text { Full cream, Non fat, Malted } \\
\text { Low, Medium, High }\end{array}$ \\
\hline $\begin{array}{l}\text { Sensory / Organoleptic } \\
\text { 5. Taste } \\
\text { 6. Appearance } \\
\text { 7. Smell }\end{array}$ & $\begin{array}{l}\text { Vanilla, Chocolate, Strawberry, Malted, } \\
\text { Other flavor } \\
\text { Soft dry powder, Liquid, Cream, Small } \\
\text { granules } \\
\text { Vanilla, Chocolate, Without, Other }\end{array}$ \\
\hline $\begin{array}{l}\text { Value / Functional } \\
\text { 8. Size } \\
\text { 9. Compositional } \\
\text { Integrity } \\
\text { 10. Package Material } \\
\text { 11.Keepability (after opening) }\end{array}$ & $\begin{array}{l}75 \mathrm{~g}, 250 \mathrm{~g}, 400 \mathrm{~g}, 500 \mathrm{~g}, 1 \mathrm{~kg} \\
\text { Yes, No } \\
\text { Aluminum foil only, Aluminum foil with } \\
\text { cardboard packet, Tetra packet } \\
1 \text { week, } 1-3 \text { week, } 3-5 \text { week, }>5 \text { Week }\end{array}$ \\
\hline $\begin{array}{l}\text { Process } \\
\text { 12. Place of Origin }\end{array}$ & $\begin{array}{l}\text { Australia, New Zealand, India, Denmark, } \\
\text { Sri Lanka }\end{array}$ \\
\hline $\begin{array}{l}\text { Text / Measurement } \\
\text { 13. Certification } \\
\text { 14. Labeling }\end{array}$ & $\begin{array}{l}\text { SLS, ISO 9001, HACCP, GMP } \\
\text { Yes, No }\end{array}$ \\
\hline $\begin{array}{l}\text { Cues } \\
\text { 15. Price }\end{array}$ & Rs. 50-100, Rs. 150-200, Rs. 250-300, > \\
\hline $\begin{array}{l}\text { 16. Brand Name } \\
\text { 17. Advertising } \\
\text { 18. Past Purchase } \\
\text { Experiences }\end{array}$ & $\begin{array}{l}\text { Anchor, Nespray, Lakspray, Red Cow, } \\
\text { Highland, Raththi, Kothmale } \\
\text { Television, Radio, Newspapers, Others } \\
\text { Yes, No }\end{array}$ \\
\hline
\end{tabular}

Source: Lakni and Jayasinghe-Mudalige (2010) 
All these create this issue multidimensional, and calls to employ multivariate data analysis techniques to explore the situation to a depth. The Multidimensional Scaling (MDS) approach - also known as a technique of Perceptual Mapping - enables an analyst to determine the perceived relative image of set of objects; thus, to transform consumer judgments of perceptual similarity into distances represented in multidimensional space (Hair et al., 1998). In light of that, we have resolved to use MDS to analyze this issue.

Practically, the first step towards carrying out a MDS is to develop right amount of combinations with the objects in hand. For the purpose of this analysis, the 4 liquid food products, namely (1) bottled water (BW); (2) pasteurized milk (PM); (3) ready-to-drink fruit juices (RTD), and (4) carbonated drinks can be set as pairs of objects as follows: $(1 \& 2)$ bottled water and pasteurized milk [BW-PM]; (1\&3) bottled water and RTD fruit juice [BW-RTD];
(1\&4) bottled water and carbonated drinks [BW-CD]; (2\&3) pasteurized milk and RTD fruit juice [PM-RTD]; (2\&4) pasteurized milk and carbonated drinks [PM-CD], and (3\&4) RTD fruit juice and carbonated drinks [RTD-CD ${ }^{1}$.

Having specified these six pairs to represent four liquid food products, next, a specific questionnaire was formulated to facilitate collection of data to carry out a MDS analysis. Following the theoretical foundation for MDS given in Hair et al. (1998), the 6 pairs identified above [i.e. (1\&2: BW-PM); (1\&3: BW-RTD); (1\&4: BW-CD); (2\&3: PM-RTD); (2\&4: PM$\mathrm{CD})$, and (3\&4: RTD-CD)] were specified in the questionnaire along with the 4 quality attributes considered (i.e. Price, Food safety, Labeling and Packaging).

A respondent to this specific set of questions was required to indicate his/her perceptions on the similarity of each product pair with respect to each and every quality attribute on a five-point liker scale

\section{Figure 0l: Information gathering sheet (extracted from the questionnaire)}

\begin{tabular}{|c|c|c|c|c|c|c|}
\hline Product Pair & Attribute & $\begin{array}{c}\text { Very } \\
\text { similar } \\
1\end{array}$ & $\begin{array}{l}\text { Moderately } \\
\text { similar } \\
2\end{array}$ & $\begin{array}{c}\text { No idea } \\
3\end{array}$ & $\begin{array}{c}\text { Moderately } \\
\text { dissimilar } \\
4\end{array}$ & $\begin{array}{c}\text { Very } \\
\text { Dissimilar } \\
\mathbf{5}\end{array}$ \\
\hline \multirow{3}{*}{$\begin{array}{l}\text { Bottled water- } \\
\text { Fresh Milk }\end{array}$} & Price & $\infty$ & $c$ & $\mathrm{CO}$ & $\varnothing$ & $\infty$ \\
\hline & $\begin{array}{l}\text { Food safety } \\
\text { Labeling }\end{array}$ & & & & & \\
\hline & Packaging & & & & & \\
\hline \multirow{3}{*}{$\begin{array}{l}\text { Bottled water- } \\
\text { Ready to drink } \\
\text { fruit juices }\end{array}$} & $\begin{array}{l}\text { Price } \\
\text { Food safety }\end{array}$ & $\infty$ & $\infty$ & $\infty$ & $\infty$ & 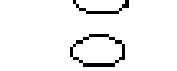 \\
\hline & Labeling & 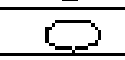 & 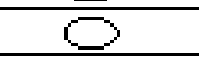 & 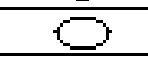 & $C$ & 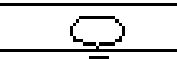 \\
\hline & Packaging & $\Leftrightarrow$ & 5 & 5 & $\Longrightarrow$ & 0 \\
\hline
\end{tabular}

\footnotetext{
${ }^{1}$ The combinations of $(1,2,3),(1,2,4)$ and $(2,3,4)$ are also possible, but did not apply in this case due to complexity of analysis.
} 
with 1 being "very similar", 2 being "moderately similar", 4 being "moderately dissimilar", 5 being "very dissimilar" and 3 being " no idea" (Figure 01).

As mentioned elsewhere, the perceptual similarities among the four liquid food products can vary with demographic and social factors of consumers. The scores provided on the likert-scale was then be used to carry out the MDS that creates perceptual maps for specific demographic and social characteristics of consumers ${ }^{2}$.

Along with perceptual maps, the outcome of MDS obtained through a statistical package generates the Stress Measurement, which reflects the proportion of variance of disparities, i.e. differences in distances between objects on the perceptual map and the similarity judgments of the respondents, not accounted for by the MDS model (Hair et al., 1998). To determine the Goodness-of-Fit of the model, the Kruskal's Stress (S) is used commonly, which can be specified as follows for each perceptual map:

$S=\sqrt{\frac{\sum\left(\boldsymbol{d}_{i j-} \boldsymbol{d}_{i j}^{\prime}\right)^{2}}{\sum\left(\boldsymbol{d}_{i j}-\boldsymbol{d}_{i j}\right)^{2}}}$

where: $\mathrm{S}$ denotes the stress measure. The right-hand side variables include: $\mathrm{d}_{\mathrm{ij}}$ " $=$ Average distance between points $i$ and $j$ on the map $\left(\sum \mathrm{d}_{\mathrm{ij}} / \mathrm{n} ; \mathrm{n}=\right.$ number of objects mapped), dij' = Derived distance from the perceptual map, $\mathrm{d}_{\mathrm{ij}}=$ Original distance based on similarity judgments.

\footnotetext{
${ }^{2}$ Both Sorting and Ranking methods can be used to gather consumer personal constructs with respect to different product attributes to investigate consumer similarity perceptions (Santosa et al., 2010). The Ranking method was, however, selected in this particular analysis.
}

\section{Data Collection and Analysis}

The questionnaire and the entire MDS approach to be used in this analysis was pre-tested to make appropriate revisions to which with the data collected from a sample of 30 consumers showing different demographic and social characteristics (e.g. gender, education) and living in an urban housing complex setting. Having purified the questions and select the best means and ways to use it with consumers with different behavioral patterns, it was administered with a sample of 300 consumers selected purposively from the urban housing complexes and residential areas located in the Homagama, Kesbawa and Maharagama Pradeshiya Shaba (in the Colombo district, Western Province) during the May - July 2011.

This process was pre-designed to collect data from equal number of males and female respondents (i.e. 150 each) to increase the precision of MDS analysis based on gender. Every effort was made to have nearly equal shares or at least sufficient numbers to represent consumer age groups preferred in the analysis. The enumerators were provided with the samples of liquid food products considered in the analysis and were trained to show each product pair before the question/s related to that particular combination was to be asked to make it convenient for the respondent to perceive the attributes of quality of concern in this study. A clear explanation about the objective and procedures to be used was given to each respondent to make sure they respond all questions without being ambiguous.

The Statistical Package for Social Sciences (SPSS) [version 13] was used to obtain the projection of similarity judgments of each consumer group on to separate perceptual map and the stress measures relevant to equation. Following the Hair et al. (1998), the solution was derived using MDS analysis involving distance matrices from 
Euclidean distance and the Pearson Correlation Analysis was carried out between the separate distances values of each and every product pairs with different demographics groups.

\section{RESULTS AND DISCUSSION}

\section{Descriptive statistics of the sample}

Out of 300 urban consumers participated to the survey, $70 \%$ completed schooling up to the Advanced Level (i.e. Secondary level) and others had a higher education and/or specific subject specific/vocational training (i.e. Tertiary level). As mentioned above, nearly $50 \%$ of both male and female respondents in the sample were aged below 45 years. Further, nearly $30 \%$ of respondents were belonging to a household that possess a monthly income greater than Rs. 30, 000 (Table 02).

The consumers in the sample used to purchase pasteurized milk in higher frequency compared to other products while bottled water showed the lowest purchasing frequency (Figure 02).
Similarity perception of product attributes Figure 03 depicts the percentage of consumers who perceived a given product combination (pair) with similarity with respect to the four quality attributes of concern.

The percentage of respondents those perceived similarly about the importance of taking into account of "price" as they purchase anyone product over the other in a given pair was highest (i.e. 79.6\%) for the pair of Pasteurized milk and RTD fruit juices (PM-RTD). The results reveal that almost $60 \%$ of respondents consider price as the most critical quality attribute as they purchase any of the product combinations taken up in this analysis. This percentage was above $75 \%$ for the (RTD-CD) and (BW-PM) and close to $60 \%$ for other three combinations.

Second to price, "food safety" becomes an important quality attribute. About $76.6 \%$ of respondents perceived food safety to be similarly important quality attribute as they decide on purchasing between bottled water and pasteurized milk (BW-PM).

Table 02. Descriptive statistics of the sample

\begin{tabular}{cccc}
$\begin{array}{c}\text { Socio-Economic } \\
\text { Characteristic }\end{array}$ & $\begin{array}{c}\text { Total Sample } \\
(\mathbf{n}=\mathbf{3 0 0})\end{array}$ & $\begin{array}{c}\text { Male (\%) } \\
(\mathbf{n}=\mathbf{1 5 0})\end{array}$ & $\begin{array}{c}\text { Female (\%) } \\
(\mathbf{n}=\mathbf{1 5 0})\end{array}$ \\
Age (Years) & 28 & & \\
$18-30$ & 22 & 25 & 32 \\
$31-45$ & 31 & 24 & 21 \\
$46-60$ & 19 & 29 & 33 \\
$>60$ & & & 15 \\
\hline Education & 70 & 70 & 71 \\
Secondary & 30 & 30 & 29 \\
Tertiary & & & \\
\hline Monthly Income (Rs.) & 22 & 15 & 30 \\
Below 15,000 & 48 & 54 & 42 \\
15,000-30,000 & 20 & 20 & 20 \\
$30,000-50,000$ & 10 & 11 & 8 \\
More than 50,000 & & &
\end{tabular}


In contrast, only about $40 \%$ of respondents perceived similarly on food safety attribute if they have to decide between pasteurized milk and carbonated drinks (PM-CD).

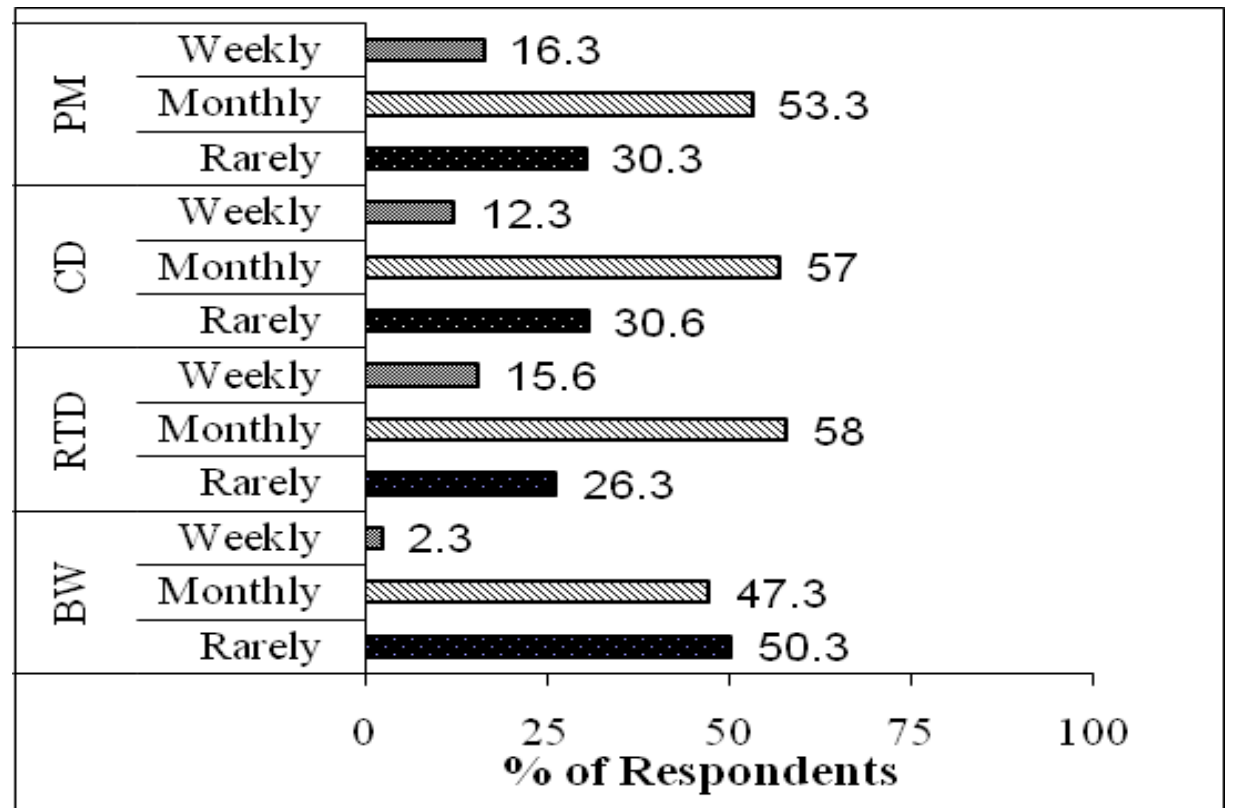

Figure 02: Frequency of use of liquid food products

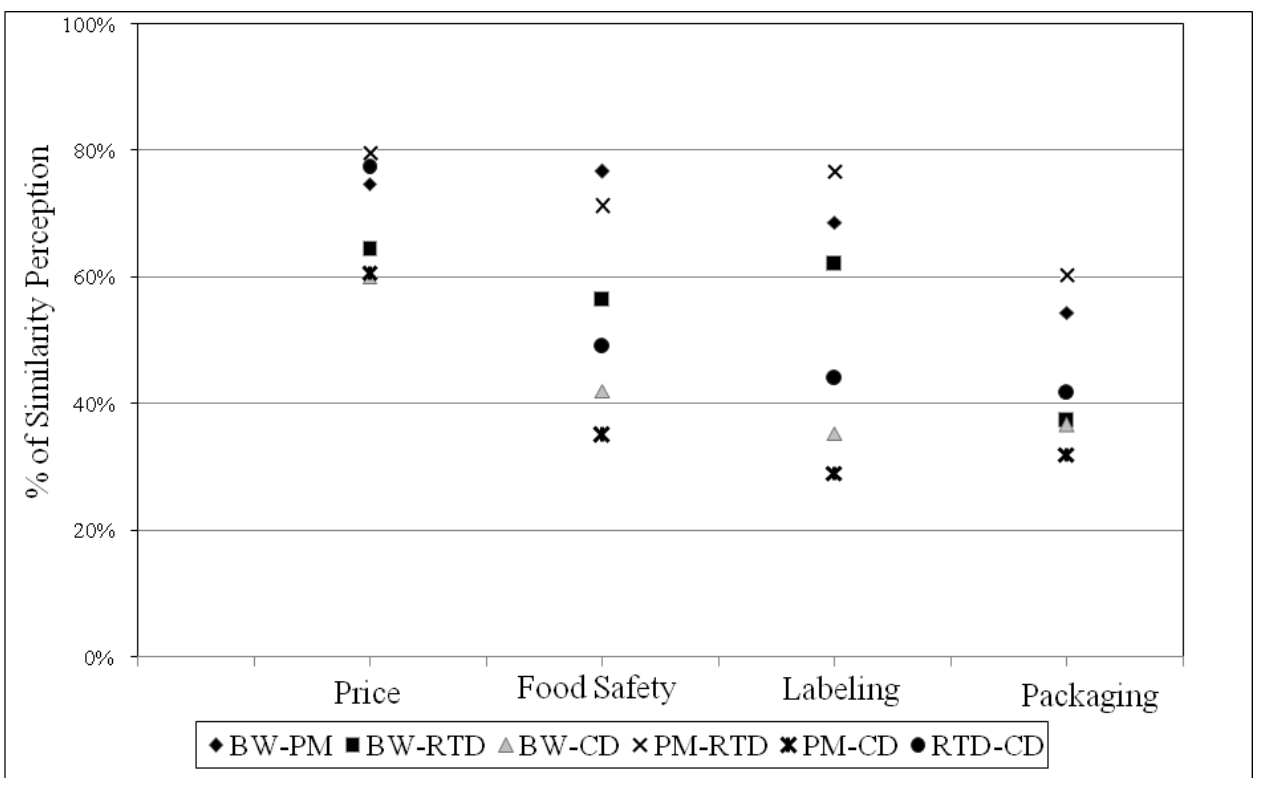

Figure 03: Similarity perception of product attributes

Note: $(B W-P M)=$ Bottled water and Pasteurized Milk, $(B W-R T D)=$ Bottled water and Ready to drink fruit juice, $(B W-C D)=$ Bottlwd water and Carbonated drinks, $(P M-R T D)=$ Pasteurized Milk and Ready to drink fruit juice, $(P M-C D)=$ Pasteurized Milk and Carbonated Drinks and $(R T D-C D)=R T D$ fruit juice and Carbonated Drinks 
With respect to "labeling", a number of inferences can be made. The similarity of consumer perceptions on any product pair with regard to this is highest $(76.6 \%)$ for Pasteurized milk and RTD fruit juices (PM-RTD). This may be due to the fact that given the relatively deteriorating nature; the consumers are more concerned of the label for information for these products. Also, more than $60 \%$ of respondents perceived similarly on it for two other pairs, namely: (BW-PM) and (BW-RTD). Further, out of four quality attributes in concern, labeling shows the greatest variation with respect to the percentage of consumers perceived similarly on any product pairs, i.e. ranging from almost $80 \%$ in the highest (PM-RTD) to nearly $30 \%$ in the lowest case of (BW$\mathrm{CD})$. In fact, for the pairs of (PM-CD) and (BW-CD), this value was recorded below $40 \%$.

With respect to "packaging", the number of consumers showing similar perceptions on any pair is low in compared to other attributes. Even for the highest case, i.e. PM-RTD, it was about $60 \%$.
Unlike labeling, the variation for it was, however, comparatively low as the lowest end represent nearly $30 \%$ consumers that is above the same for labeling attribute.

\section{Outcome of Multidimensional Scaling Analysis}

Perceptual Maps were obtained to represent the socio-economic variables of gender and educational for all product pairs (Figure 04).

The different combinations of quality attributes considered in the analysis are represented by a point in the map. The distances between these points are calculated to achieve an optimal representation of similarity as captured by the raw data. The two dimensional solution represents items that are perceived close together as subjectively similar and those that were far apart to be subjectively dissimilar. These show that for price and food safety attributes as they were rated at the highest level by respondents to this particular analysis. The estimates of Stress Value and distances between each product pair were reported in Table 03 .

Table 03. Outcome of the Multid imensional Scaling

\begin{tabular}{|c|c|c|c|c|c|c|c|}
\hline \multirow{2}{*}{$\begin{array}{c}\text { Socio- } \\
\text { Economic } \\
\text { Character istic }\end{array}$} & \multirow{2}{*}{$\begin{array}{l}\text { Stress } \\
\text { Value }\end{array}$} & \multicolumn{6}{|c|}{$\begin{array}{l}\text { Distance Between Product Pairs Based on the } \\
\text { Price and F ood Safety Dimensions }\end{array}$} \\
\hline & & BW-PM & BW-RTD & BW-CD & PM-RTD & PM-CD & RTD-CD \\
\hline Male & 0.0838 & 0.852 & 1.180 & 0.910 & 0.809 & 1.240 & 0.855 \\
\hline Female & 0.0799 & 0.815 & 1.200 & 0.923 & 0.813 & 1.221 & 0.877 \\
\hline Tertiary & 0.0839 & 0.846 & 1.171 & 0.911 & 0.819 & 1.249 & 0.851 \\
\hline \multirow[t]{3}{*}{ Secondary } & 0.0798 & 0.814 & 1.198 & 0.921 & 0.816 & 1.222 & 0.876 \\
\hline & & \multicolumn{6}{|c|}{$\begin{array}{c}\text { Distance Between Product Pairs Based on the } \\
\text { Labeling and Packaging Dimensions }\end{array}$} \\
\hline & & BW-PM & BW-RTD & BW-CD & PM-RTD & PM-CD & RTD-CD \\
\hline Male & 0.1936 & 0.984 & 0.926 & 0.606 & 1.007 & 0.528 & 0.53 \\
\hline Female & 0.1052 & 1.097 & 0.781 & 0.760 & 0.770 & 0.764 & 1.077 \\
\hline
\end{tabular}


The results show that there is no significant difference with respect to males and females as they perceive on a given object (Figure 04A and 04B). Further, it shows that two levels of education (i.e. Secondary and Tertiary) were correlated highly (i.e. 0.991 ) at $95 \%$ significant level. This highlights that similarity perceptions amongst the consumers, irrespective of their gender, was highest between pasteurized milk and RTD fruit juices for these two attributes, while it was the least for pasteurized milk and carbonated drinks. Both males and females were perceived that the price plays a highly positive role as they purchase carbonated drinks, but for the same they did not care of food safety.

This may be explained as consumers prefer a certain brand and they judged that it solves their issues with respect to food safety (i.e. credence characteristic of food safety become an experience characteristic).

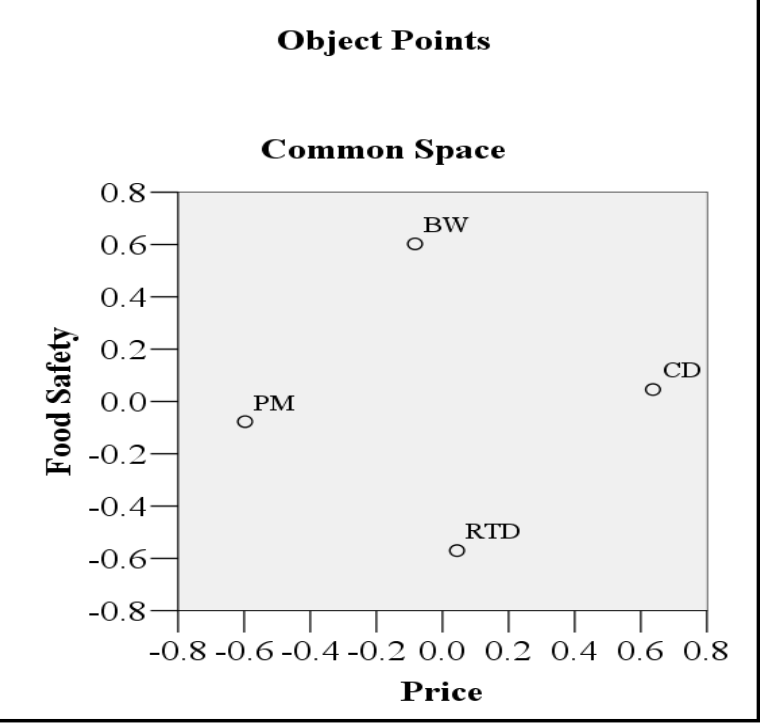

Figure 04A: Perceptual map on Food safety and Price for males
However, this is otherwise as we consider about the bottled water as consumers pay more attention to food safety in compared to price.

The reasons may be price of unit of a bottled water, irrespective of brand, is almost similar, but given credence characteristic and a necessity good with high sensitivity towards hygiene, they pay more attention on food safety attribute. The results revealed that education did not have a significant impact in this respect (Figure 04C and 04D).

Irrespective of the level of education, consumers judged that both price and food safety were highly important as they decide on purchasing the pasteurized milk and RTD fruit juices and the lowest similarity perception was recorded between the pasteurized milk and carbonated drinks.

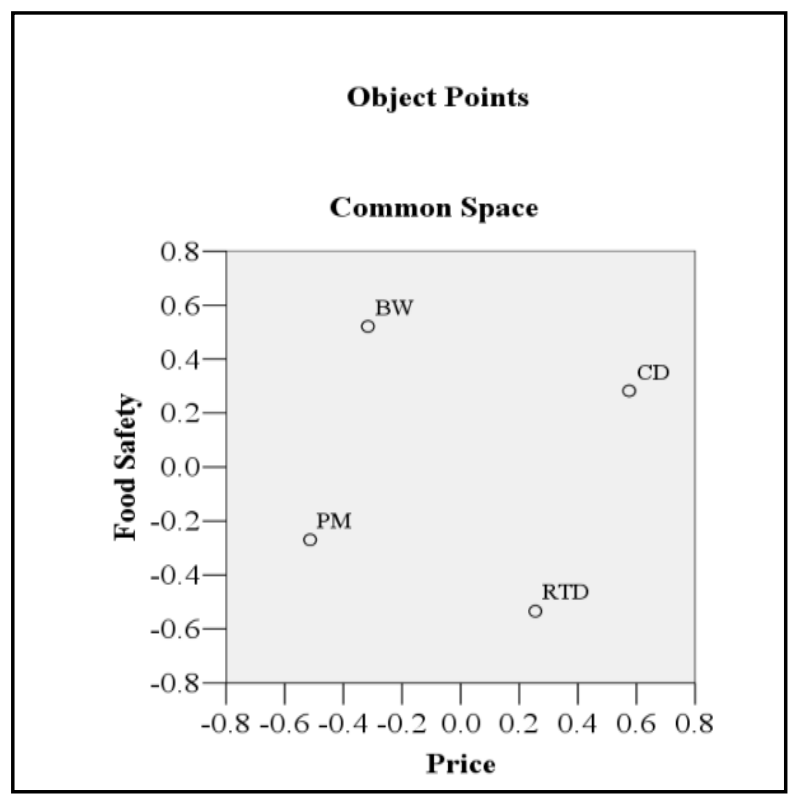

Figure 04B: Perceptual map on Food safety and Price for females 


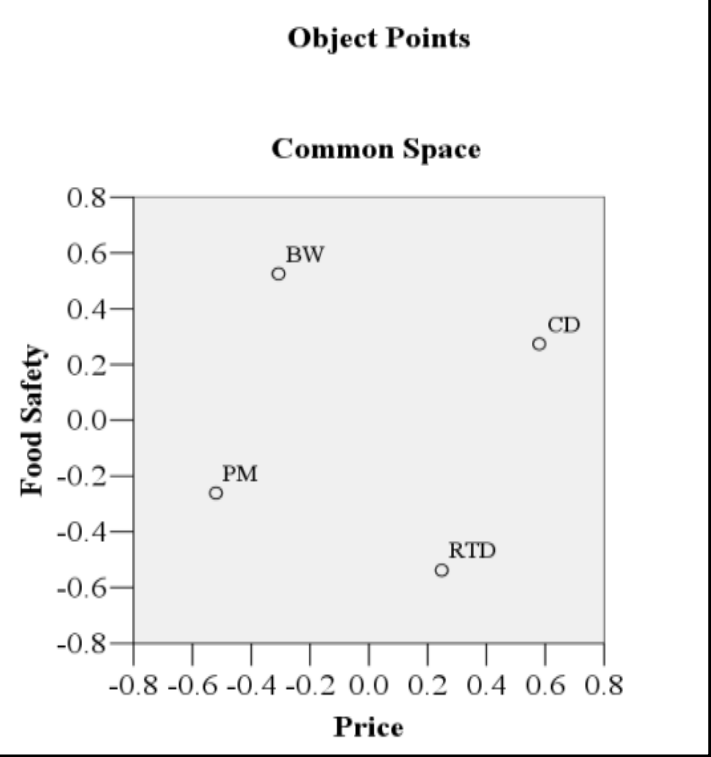

Figure 04C: Perceptual map on Food safety and Price for group with secondary education

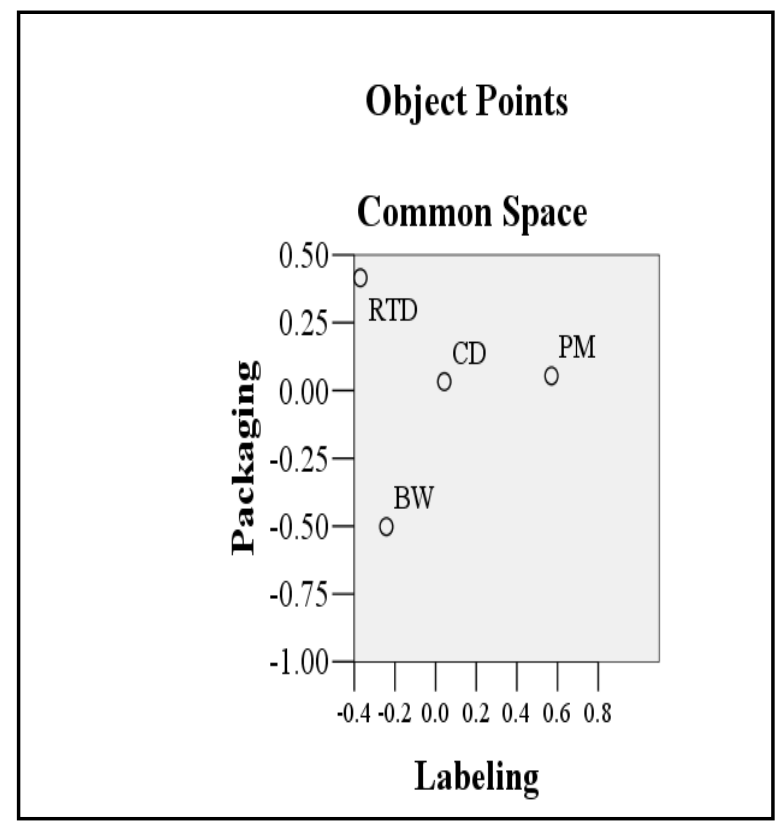

Figure 4E. Perceptual map on Packaging and Labeling for males

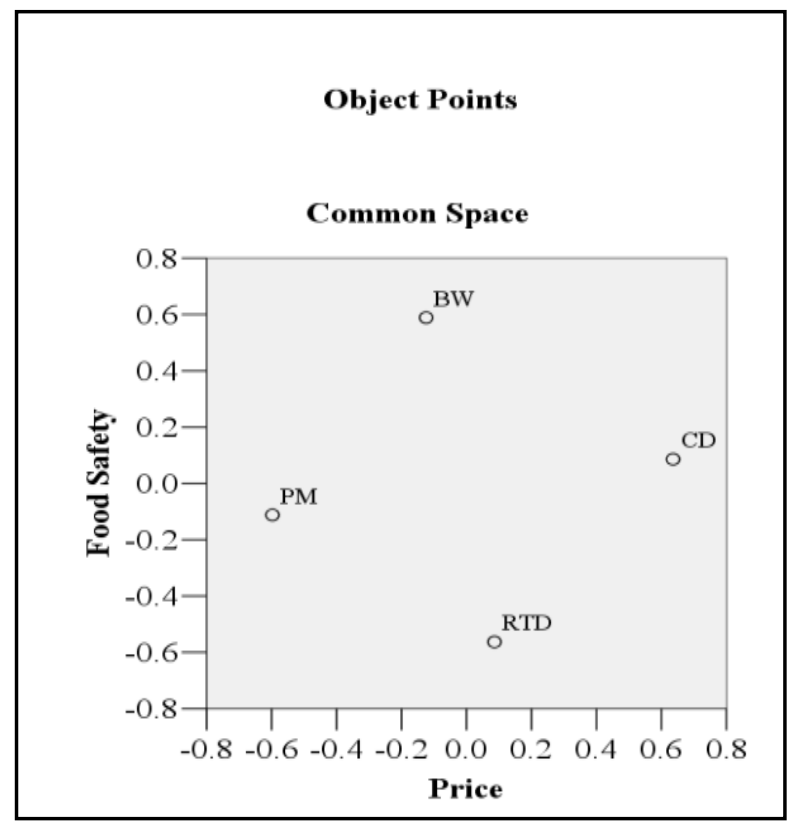

Figure 4D. Perceptual map on Food safety and Price for group with tertiary education

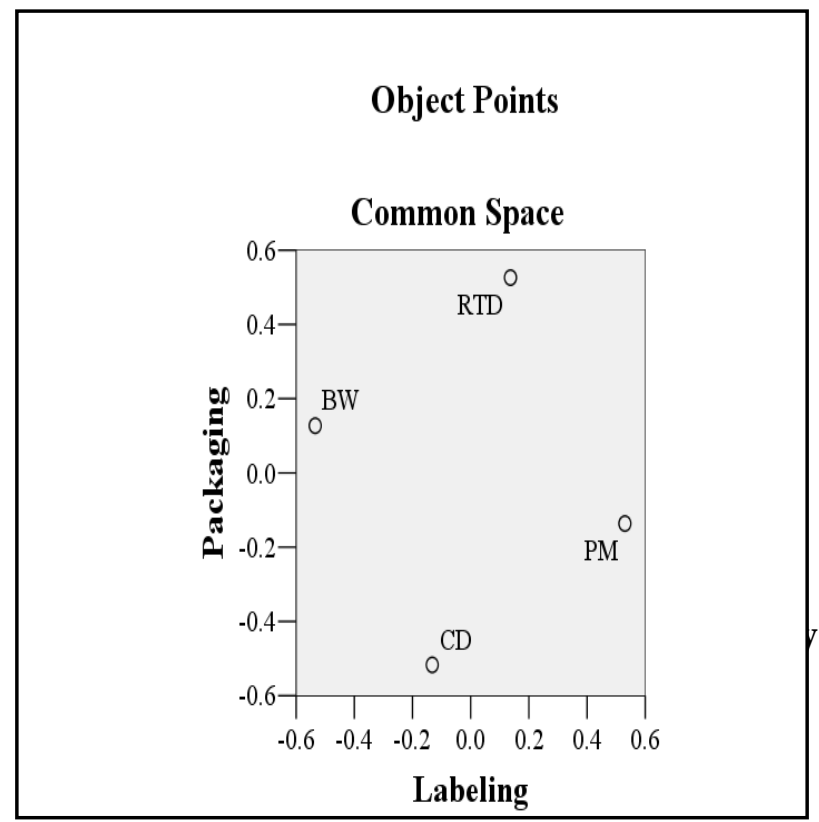

Figure 4F. Perceptual map on Packaging and Labeling for females 
However, at $95 \%$ confidence level, there is a significant difference between males and females on their perception of similarity between labeling and packaging of the four products in concern (Figure 4E and 4F). Interestingly, irrespective of the gender, both groups indicated a high positive importance on packaging for RTD fruit juices while considering the labeling to be most important for pasteurized milk. Where carbonated drinks and bottled water are of concern, the males perceive relatively higher importance on packaging of carbonated drinks while females did so for bottle water. However, both groups paid more attention on both packaging and the product label during the purchase of pasteurized milk for consumption in relation to other products.

\section{CONCLUSIONS}

The results revealed that the respondents perceived pasteurized milk and RTD fruit juices to be relatively similar in terms of price and food safety attributes irrespective of their socio demographic characteristics such as gender and educational level. The results also suggest that the purchasing behavior of RTD fruit juices and pasteurized milk were very similar with respect to the price, labeling and packaging attributes. Consumers consider these attributes to be more or less similar with respect to these two products due to the deteriorating nature of pasteurized milk and RTD fruit juices. As consumers are more concerned on and aware of food quality standards (i.e. SLS) of bottled water, and the knowledge of hazardous chemical compounds in carbonated drinks, the food safety attribute had a significant impact on the buying behavior of bottled water and carbonated drinks. Thus, bottled water shows the nature of a credence good as the true quality of the product is never known even after purchase and consumption where the quality of the other three products could be experienced.

Consumers perceived the price factor to be equally important in purchasing decisions across all four products. Irrespective of the socio-demographic characteristics consumers paid more attention on both labeling and packaging attributes during purchase of pasteurized milk. To the extent that these findings apply more generally, it is evident that remaining liquid food product producers and potential entrants into the market should pay special attention to the particular attributes in catering their client-base. Attractive prices should be applied to the all four products as price plays an important factor specially in marketing (i.e. segmentation and pricing). It is important that the liquid food producers always shed attention on food quality attributes as well as the physical and aesthetic characteristics of the liquid food products in promoting these products to the market.

\section{REFERENCES}

Abayasekara, C. L., Herath, W. H. M. A. T., Adikaram, C. R., Illapperuma, S. C., Sirisena, A. D., and Rajapur, S. G. (2007). Microbiological quality of bottled water in Sri Lanka: A preliminary survey. In: Proceeding of $12^{\text {th }}$ Research Sessions. 30 November, 2007. University of Peradeniya, Sri Lanka.

Buzby, J. C. (2003). International trade and food safety: economic theory and case studies. Agricultural Economic Report - No. 828. Economic Research Service, United States Department of Agriculture.

Caswell, J. A. 1998. Valuing the Benefits and Costs of Improved Food Safety and Nutrition. Australian Journal of Agriculture and Resource Economics, 42 (December):409-474. 
Darby, M. R., and Karni, E. (1973). Free Competition and the optimal amount of fraud. Journal of Law and Economics, 16, 67-88.

Department of Census and Statistics (2009). Household Income and Expenditure Survey (2009/2010), Department of Census and Statistics, Ministry of Finance and Planning, Sri Lanka. Available at: htpp://www.statistics.gov.lk/HIES/PreRepotHIES2009Eng.pdf.

Hair, J. F., Anderson, R. E., Tatham, R. L., and Black, W. C. (1998). Multivariate Data Analysis. $5^{\text {th }}$ Ed. New Jersey. Prentice-Hall.

Henson, S. and Caswell, J. (1999). Food safety regulation: an overview of contemporary issues. Food Policy 24: 589 - 603

Kariyawasam, S., Jayasinghe-Mudalige, U. K., and Weerahewa, J. (2007). Use of Caswell's classification on food quality attributes to assess consumer perceptions towards fresh milk in tetra- packed containers. Journal of Agricultural Sciences, 3, 43-46.

Lakni, W. A. K. I., and Jayasinghe-Mudalige, U. K. (2009). Customer-defined quality of food: An empirical investigation based on KANO Analytical methods for milk powder. Journal of Agricultural Sciences, 4, 45-58.

Nelson, P. (1970). Information and consumer behavior. Journal of Political Economics, 78, 311-329. 